\title{
NÓS POR NÓS MESMOS: EVIDÊNCIAS DA PRODUÇÃO ACADÊMICA SOBRE O EXAME NACIONAL DE DESEMPENHO DE ESTUDANTES (ENADE) EM CIÊNCIAS CONTÁBEIS
}

\section{WE BY OURSELVES: EVIDENCE OF ACADEMIC PRODUCTION ON THE NATIONAL EXAM OF STUDENT PERFORMANCE IN ACCOUNTING}

\section{ANTONIO GUALBERTO PEREIRA \\ Doutor em Controladoria e Contabilidade - Faculdade de Economia, Administração e Contabilidade - FEA/USP \\ Professor do Programa de Pós-Graduação em Contabilidade - Universidade Federal da Bahia (UFBA) \\ Orcid: http://orcid.org/0000-0003-2354-6797 \\ E-mail: antoniopereira@ufba.br}

Faculdade de Ciências Contábeis, Avenida Reitor Miguel Calmon, s/n - Vale do Canela,

Salvador/Bahia, CEP: 40.110-100

\section{TANIA NUNES}

Doutora em Controladoria e Contabilidade

Professora dos cursos de Graduação e Pós-Graduação da Escola de Gestão e Negócios Instituto Federal Farroupilha

Orcid: https://orcid.org/0000-0003-3238-8807

E-mail: tania.nunes@usp.br

\section{RAFAEL ROCHA SIMÕES}

Mestrando em Ciências Contábeis

Universidade Federal da Bahia (UFBA)

Orcid: https://orcid.org/0000-0003-4814-1200

E-mail: fael_812@yahoo.com.br

Submissão: 01/04/2020. Revisão: 13/10/2020. Aceite:29/12/2020. Publicação: 01/03/2021.

DOI: http://dx.doi.org/10.22277/rgo.v14i1.5355

\section{RESUMO}

O presente estudo realizou uma revisão sistemática da produção acadêmica acerca do Exame Nacional de Desempenho de Estudantes na área de Contabilidade e, para tanto, explorou os seguintes objetivos específicos: (i) escanear os periódicos nacionais com maior classificação no Qualis -CAPES; (ii) analisar quantitativa e qualitativamente os artigos localizados, incluindo a verificação de indicadores bibliométricos propostos na literatura; (iii) sintetizar graficamente a evolução da produção sobre esse tópico no período. O método de análise foi descritivo e bibliométrico, abarcando mais de dez anos de produção acadêmica sobre o ENADE em periódicos nacionais, além de teses de doutorado em Ciências Contábeis. Identificou-se um crescimento da produção sobre o ENADE nos últimos anos. Os achados referentes a indicadores bibliométricos específicos mostram que as Leis de Lotka, Bradford e Zipf são ratificadas. Ao final, é apresentado um quadro geral da produção acadêmica sobre o ENADE em mais de uma década, fornecendo indicativos de tendência para a pesquisa na área.

Palavras-chave: ENADE. Ensino Superior em Contabilidade. Produção Acadêmica. 


\begin{abstract}
This study aims at a systematic review of the academic production regarding the National Exam of Student Performance (ENADE, in the acronym in Portuguese) in Accounting. There were three specific goals: (i) to track national journals with the highest ranking in Qualis CAPES; (ii) to analyze quantitatively and qualitatively the papers found, including the verification of bibliometric indicators proposed in the literature; (iii) to get a graphical summary of the evolution of production on the theme in the period. We performed a descriptive and bibliometric analysis covering more than ten years regarding the National Exam on top Brazilian journals, in addition to Accounting PhD theses. In recent years, there was a growth in studies about the National Exam. Findings regarding bibliometric indicators show that Lotka, Bradford and Zipf Laws were confirmed. As a final mark, we present a general framework of the academic production on the National Exam, providing indicative trends to the research in this area.
\end{abstract}

Keywords: National exam. Accounting. Academic journals.

\title{
1 INTRODUÇÃO
}

O contexto histórico configurado pela expansão da graduação e da pós-graduação stricto sensu em cursos de Ciências Contábeis e por mudanças no campo de atuação do contador quanto à normatização e ao processo de convergência com os padrões internacionais exigem uma formação qualificada que acompanhe essa dinâmica. Miranda (2011) afirma ser essa situação um fator que influencia o ensino da Contabilidade. Os dados do Censo da Educação Superior 2015, divulgada pelo Instituto Nacional de Estudos e Pesquisas Educacionais (INEP), expõem tal fato: naquele ano, havia um total de 8.033 .574 matrículas. Do universo de matrículas, 358.452 correspondiam ao curso de Ciências Contábeis, ou seja, $4,47 \%$ dos ingressantes do ensino superior eram deste curso. Neste mesmo ano, 966 instituições ofertavam 1.274 cursos de Ciências Contábeis (correspondendo 3,8\% de todos os cursos de nível superior ofertados). Além disso, 54.789 discentes estavam em situação de conclusão de curso. Os dados dimensionam a participação do curso de Ciências Contábeis no quadro geral do ensino superior brasileiro e, por conta da sua relevância, surge a preocupação com a qualidade dos cursos ofertados que, entre outras formas, pode ser analisada por meio do Exame Nacional de Desempenho de Estudantes - ENADE.

O Exame avalia o rendimento de ingressantes e concluintes dos cursos de graduação, em relação aos conteúdos programáticos, habilidades e competências adquiridas em sua formação. O exame é aplicado desde 2004, sendo que ocorre trienalmente para um mesmo curso analisado. Juntamente com o exame, as respostas ao Questionário do Estudante (elemento de preenchimento obrigatório para quem realiza o ENADE) se configuram em elementos fundamentais para calcular os indicadores de educação superior, como por exemplo:

- Conceito ENADE - indicador de qualidade calculado a partir dos desempenhos dos estudantes concluintes dos cursos de graduação no ENADE;

- Conceito Preliminar de Cursos (CPC) - indicador de qualidade que agrega o Conceito ENADE, titulação e regime de trabalho do corpo docente, percepções dos estudantes sobre a organização didático-pedagógica, infraestrutura e as oportunidades de ampliação da formação acadêmica e profissional; e 
Nós por nós mesmos: evidências da produção acadêmica sobre o exame nacional de desempenho de estudantes (ENADE) em Ciências Contábeis

- Índice Geral de Cursos avaliados da instituição (IGC) - calculado por Instituição de Ensino Superior (IES), considera a média dos CPC's dos cursos avaliados da instituição, no triênio de referência, ponderada pelo quantitativo de matrículas, mais a média dos conceitos da avaliação trienal da CAPES dos programas de pósgraduação stricto sensu, relativizada pelo número de matrículas.

Esses índices são divulgados pelo INEP e regulamentados pela Portaria Normativa $\mathrm{n}$-40 do Ministério da Educação, republicada em 2010. Pela sua capacidade para descrever potencialidades e lacunas na formação discente superior, tais indicadores são ferramentas auxiliadoras no desenvolvimento de políticas públicas voltadas para este nível de ensino.

Pesquisas de natureza bibliométrica oferecerem insumos relevantes para que os pesquisadores direcionem seus esforços de pesquisa. Estudos mais aprofundados e aplicações empíricas requerem, inicialmente, o conhecimento sobre o estado da arte naquele campo de pesquisa. Nesse contexto, o presente trabalho propõe a seguinte questão de pesquisa: qual a tendência e as características da produção acadêmica que enfoca o Exame Nacional de Desempenho de Estudantes (ENADE) na área de Ciências Contábeis?

Este estudo possui como objetivo geral desenvolver um levantamento sistemático da produção acadêmica sobre o ENADE na área de Contabilidade. Constituem os objetivos específicos: (i) escanear os periódicos nacionais com maior classificação no Qualis - CAPES; (ii) analisar quantitativa e qualitativamente os artigos localizados; (iii) sintetizar graficamente a evolução da produção sobre esse tópico no período. A vigência superior a uma década do ENADE permite coletar material suficiente para proceder com a análise proposta, a qual é justificada pela necessidade periódica de se realizar uma reflexão acerca da produção existente, a fim de identificar lacunas (e consequentes oportunidades de pesquisa), temas e abordagens adotados com maior frequência, entre outros.

A investigação foi conduzida em periódicos nacionais da área contábil - ou, mais amplamente, de Negócios - abrangendo mais de uma década de existência do exame (de 2004 a 2017). Foram priorizados os periódicos possuidores de mais alto nível de classificação seguindo o Qualis, da Coordenação de Aperfeiçoamento de Pessoal de Nível Superior (CAPES).

A relevância deste estudo consiste na disponibilização criteriosa da análise acadêmica sobre o objeto em questão, de modo a constituir uma forma prática de consulta para direcionamento posterior às fontes neste citadas, facilitando futuras pesquisas com temática semelhante. Além disso, entende-se que a análise produzida seja do interesse de coordenadores de curso superior em Ciências Contábeis e áreas correlatas, principalmente, tendo-se em vista a recente expansão do ensino superior, bem como da pós-graduação stricto sensu na área; os baixos índices de aprovação no exame de certificação - cuja obrigatoriedade iniciou-se em 2010 - também inspiram maior atenção por parte dos coordenadores quanto à qualidade da educação que ofertam em seus cursos.

A seção 2, que se segue a esta introdução, aborda estudos anteriores sobre o tema e discute acerca das bases conceituais do ENADE. A seção 3 descreve os procedimentos metodológicos aplicados no estudo, comtemplando o protocolo da análise bibliométrica. A seção 4 apresenta a análise e discussão dos resultados e, finalmente, a seção 5 traz as conclusões e limitações do estudo.

\section{REVISÃO DA LITERATURA}


Nesta seção, apresenta-se uma visão geral sobre avaliação educacional, seguida por um breve histórico do ENADE. Também, discorre-se sobre bibliometria e relacionam-se trabalhos anteriores na área contábil que fizeram uso de abordagem bibliométrica.

\subsection{AVALIAÇÃO EDUCACIONAL}

Avaliar pressupõe a coleta e análise de informações para proporcionar julgamento sobre programas ou projetos, estando ou não associados a financiamento (LEVITON; BORUCH, 1983; FREITAS et al., 2012). A qualidade do ensino e da pesquisa está no cerne da educação superior e, consequentemente, existe um interesse crescente em desenvolver indicadores de desempenho para medir o resultado destas duas atividades (BYRNE; FLOOD, 2003). Os resultados das avaliações podem servir de inputs para auxiliar na tomada de decisões sobre as supracitadas dimensões.

A avaliação de programas educacionais, de acordo com Alkin e Vo (2017), pode ser classificada como somativa ou formativa. A avaliação formativa visa prover informações para a melhoria de programas, enquanto a avaliação somativa auxilia em decisões, como por exemplo, continuar ou abandonar um programa. Uma analogia interessante para diferenciar avaliação somativa e formativa (embora elas não sejam mutuamente excludentes) é apresentada por Stake e Becher (2017), da Universidade de Minnesota: “Quando o cozinheiro aprecia a sopa, temos uma avaliação somativa. Quando um convidado aprecia a sopa, temos uma avaliação formativa". Assim sendo, o "cozinheiro", como figura que representa os formuladores de políticas públicas, definem, com base na sua expertise, uma combinação de elementos (estrutura física, capacitação pedagógica, currículo, etc.) que considera adequado para alcançar o produto final (a "sopa" ou o desempenho educacional). Por outro lado, os convidados para apreciar a "sopa" (no caso, os alunos), podem indicar que aquela combinação precisa ser ajustada. O "cozinheiro" ou formulador de políticas públicas pode modificar as combinações a partir de tais outputs.

No contexto da presente pesquisa, que tem como locus de pesquisa o ENADE, tanto a avaliação formativa quanto a somativa estão presentes. A dimensão somativa pode ser percebida quando o desempenho insuficiente por períodos consecutivos de uma IES conduz os órgãos governamentais a descredenciá-la. A dimensão formativa, por sua vez, está associada à perspectiva de como os estudantes das IES se comportam, em termos de desempenho, a determinados percentuais de docentes com titulação de doutor ou de mestre, ou mesmo a uma maior proporção de docentes atuando em tempo integral.

Avaliação educacional pode ser definida como o ato sistemático de coletar informações sobre a natureza e a qualidade de objetos educacionais e pode servir a muitas necessidades em vários níveis do sistema educacional, resultando em cinco grandes funções. Tais funções estão relacionadas à tomada de decisão, ações de melhoria, prestação de contas, profissionalização e certificação (NEVO, 1983)

A avaliação da qualidade do sistema de ensino se configura como estratégia relevante para o estabelecimento de métricas de desempenho e para auxiliar o processo de monitoramento de reformas e políticas educacionais (CASTRO, 1998; SANTOS, 2012). Configura-se, portanto, como elemento quantificador e qualificador da eficiência e da efetividade educacional. No Brasil, a avaliação da educação tem se caracterizado por focalizar na prestação de contas e por buscar medir a qualidade das instituições de ensino.

Sousa (2003) aponta aspectos negativos da avaliação educacional nos moldes de testes padronizados, como vem sendo implementado no Brasil. Para a autora, este modelo de avaliação apresenta baixo potencial pedagógico e direciona a formulação do currículo pelas 
Nós por nós mesmos: evidências da produção acadêmica sobre o exame nacional de desempenho de estudantes (ENADE) em Ciências Contábeis

IES, além de atuar como mecanismo de controle governamental. Contrapõe-se, portanto, à autonomia pedagógica e didática requerida pelas unidades de ensino e acaba por delimitar as competências, habilidades e atitudes que devem ser legitimadas pela escola.

\subsection{BREVE HISTÓRICO DO ENADE}

De acordo com Limara e Brito (2005) citados por Rothen e Barreyro (2010), tendo a característica de avaliar tanto o ingressante quanto o concluinte, na sua proposta original o ENADE se configuraria como o mecanismo de avaliação dinâmico, pois avaliaria o "valor adicionado" durante o curso. Para Brito (2008) é dado enfoque ao processo de aprendizagem e não ao resultado, passando a ser uma avaliação para aprendizagem. Rothen e Barreyro (2010) ainda afirmam que, com a criação e implantação do Indicador de Diferença entre os Desempenhos Observado e Esperado (IDD) - e do Conceito Preliminar de Cursos (CPC), é resgatado o caráter regulador do modelo de avaliação antecessor (Provão) da educação superior. Na Figura 1 é sintetizada a composição dos indicadores de avaliação do SINAES.

Figura 1 - Composição dos indicadores de avaliação do SINAES

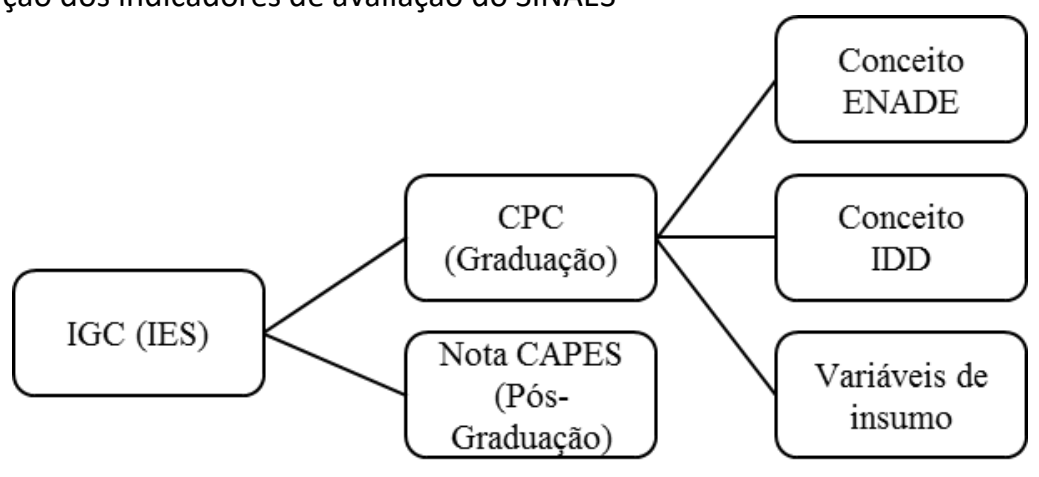

Fonte: Miranda (2011).

Esta mesma característica regulatória pode ser verificada no parágrafo único do artigo 2 을 Lei do SINAES, quando é afirmado que os resultados das avaliações do SINAES:

[...] constituirão referencial básico dos processos de regulação e supervisão da educação superior, neles compreendidos o credenciamento e a renovação de credenciamento de instituições de educação superior, a autorização, o reconhecimento e a renovação de reconhecimento de cursos de graduação.

Em 2014, o Ministério da Educação (MEC) divulgou os resultados de indicadores da avaliação aplicada em 2013, e se fundamentando nessas informações, anunciou medidas de supervisão sobre 280 cursos de graduação que obtiveram desempenho conceitual inferior a 3 (PORTAL MEC, 2014). Em 2015, 756 cursos avaliados em 2014 foram classificados com desempenho insatisfatório (CPC inferior a 3). As IES ofertantes de tais cursos ficaram impedidas de abrirem novas vagas e tiveram suspensos os contratos de programas com o governo federal como Universidade para Todos (PROUNI), Fundo de Financiamento Estudantil (FIES) e Programa Nacional de Acesso ao Ensino Técnico e Emprego (PRONATEC) (MINISTÉRIO DA EDUCAÇÃO E CULTURA, 2015).

Este monitoramento por parte do MEC permite, inclusive, observar instituições que merecem receber aporte de recurso em termo de bolsas - alocação de recursos por parte do governo federal/sociedade. Isso justifica o impacto social deste tipo de avaliação de cursos/IES. 
O ENADE está se consolidando ao longo do tempo como mecanismo de política educacional e à medida que demandas novas surgem, sofre algumas alterações como forma de adequação ao modelo educacional nacional. Entre as mais recentes alterações estão: o preenchimento obrigatório do questionário do estudante e a publicação do Manual do Estudante desde 2014 (PORTAL MEC, 2016).

Rodrigues e Peixoto (2009) apresentam evidências, a partir de dados coletados junto aos coordenadores de curso, de que as questões presentes no ENADE privilegiam conhecimentos mais generalistas em detrimento de conhecimentos específicos das áreas. Neste sentido, o uso da síntese dos dados do ENADE para fins de melhorar a gestão educacional é algo ainda sujeito a controvérsias e merece ser melhor investigado.

Outro ponto polêmico em relação ao ENADE é o boicote de algumas instituições, justamente por razões de discordância sobre a metodologia adotada. Leitão, Moriconi, Abrão e Silva (2010) avaliam que, como o percentual de alunos aderentes ao boicote, de forma geral, nunca foi superior a $3,5 \%$, ele não é significativo. Tal ponto de vista não é consensual, dado que Pedrosa (2013) afirma haver "níveis altíssimos de boicote" por parte de instituições como Unifesp, Unesp, UFRJ, UFMG.

Portanto, há diversas nuances e perspectivas que trazem relevância a este tema, ao tempo em que demandam um diagnóstico de abordagens de estudos, sendo o mapeamento da produção nesta temática uma estratégia capaz de fornecer insumos para os pesquisadores e demais interessados no tema.

\subsection{BIBLIOMETRIA}

Os avanços das ciências não são apenas progressivos, mas também reflexivos (BRUYNE et al., 1991 citados por THEÓPHILO; IUDÍCIBUS, 2005), de modo que o desenvolvimento das ciências depende, além das investigações que visam seu crescimento linear, de estudos que se dediquem à reflexão crítica sobre o conhecimento nelas produzido (THEÓPHILO; IUDÍCIBUS, 2005). Foi a partir da necessidade de se avaliar as atividades dessa produção e comunicação científicas, que várias técnicas quantitativas e qualitativas foram desenvolvidas (ARAúJO, 2006). Dentro do contexto das técnicas quantitativas a bibliometria se caracteriza como uma forma de avaliação objetiva da produção científica, diferenciando-se de métodos mais subjetivos de avaliação.

Conforme Okubo (1997), a bibliometria pode ser considerada ferramenta que permite verificar o estado em que se encontra a ciência e a tecnologia num dado momento, em que a produção da literatura científica pode ser observada num todo e a um dado nível de especialização. Por exemplo, a produção de um país em relação ao mundo, de uma instituição em relação ao país, etc. Para Tague-Sutcliffe $(1992$, p.1) a "Bibliometria é o estudo dos aspectos quantitativos da produção, disseminação e uso da informação registrada. Desenvolve modelos matemáticos e medidas para esses processos e então usa os modelos e medidas para previsão e tomada de decisões". Fonseca (1986) menciona que o termo bibliometria foi popularizado por Pritchard (1969) após discussões sobre a substituição do termo 'bibliografia estatística' que vinha sendo utilizado até então. Assim, Pritchard (1969, p. 348) sugere que o termo bibliometria seja entendido como "a aplicação de métodos matemáticos e estatísticos a livros e outros meios de comunicação".

Como método de avaliação da produção científica, a bibliometria é originária de observações empíricas a partir das quais foram desenvolvidos diversos parâmetros, denominados de indicadores bibliométricos como, por exemplo, número de citações, quantidade de artigos, autoria, região geográfica dos pesquisadores, instituição de origem etc. 
Nós por nós mesmos: evidências da produção acadêmica sobre o exame nacional de desempenho de estudantes (ENADE) em Ciências Contábeis

Alguns desses parâmetros foram estruturados em Leis que são responsáveis por descrever, quantificar e prognosticar as publicações acadêmicas de uma determinada área de conhecimento, servindo assim como meio de verificação do estado atual e os possíveis rumos a serem tomados na produção científica (GUEDES; BORSCHIVER, 2005).

\subsection{ESTUDOS ANTERIORES}

Variados autores da área contábil se dedicaram à realização de estudos bibliométricos: Nascimento, Junqueira e Martins (2010), Faria, Gomes, Dias Filho e Albuquerque (2011), Girão e Machado (2013), Santos, Beuren, Nardi e Vicenti (2016). Ilustramos, a seguir, três dos mais recentes trabalhos com este enfoque:

Ribeiro (2014) investigou o tema Contabilidade Internacional, no período de 1999 a 2013 fazendo uso, de técnicas bibliométricas e análise de rede social, de modo a traçar um perfil que incluía a identificação dos tópicos predominantes em periódicos brasileiros.

Já na área de auditoria, Ribeiro (2015) analisou 107 estudos nacionais, observando a evolução do tema ao longo de 14 anos, compreendendo instituições, periódicos e autores mais profícuos.

Finalmente, Ritta e Lavarda (2017) verificaram os aspectos da produção científica sobre controle gerencial, mediante análise dos temas de pesquisa mais frequentes, distribuição temporal das publicações, autores mais produtivos, tipos de fonte de consulta, artigos, livros e periódicos mais referenciados, e teorias organizacionais mais utilizadas.

\section{PROCEDIMENTOS METODOLÓGICOS}

Ontologicamente, esta pesquisa classifica-se como idealista, sendo construtivista do ponto de vista epistemológico, de modo que, nas interpretações dos dados apresentados, temos consciência de que há um subjetivismo inerente àquele que as emite. Com relação aos aspectos práticos, trata-se de pesquisa descritiva e documental (GIL, 2002), objetivando fornecer o mapeamento da produção acadêmica nacional referente ao ENADE entre 2004 e 2017.

\subsection{POPULAÇÃO E AMOSTRA}

O exame da literatura nacional concentrou-se nos periódicos com maior classificação de acordo com os critérios do Qualis da CAPES (2013 a 2016), mais especificamente, aqueles com classificação nos estratos A1, A2 e B1, além das produções acadêmicas em nível de doutoramento de cursos stricto sensu das IESs brasileiras.

Quadro 1 - Relação de periódicos analisados

\begin{tabular}{|l|c|c|c|}
\hline \multicolumn{1}{|c|}{ PERIÓDICO } & INSTITUIÇÃO & ISSN & QUALIS \\
\hline Advances in Scientific and Applied Accounting - ASAA & ANPCONT & $\begin{array}{c}1983- \\
8611\end{array}$ & A2 \\
\hline Brazilian Business Review - BBR & FUCAPE/ES & $\begin{array}{c}1808- \\
2386\end{array}$ & A2 \\
\hline Contabilidade Vista \& Revista & UFMG/MG & $\begin{array}{c}0103- \\
734 X\end{array}$ & A2 \\
\hline Revista Brasileira de Gestão de Negócios - RBGN & FECAP/SP & $\begin{array}{c}1983- \\
0807\end{array}$ & A2 \\
\hline Revista Contabilidade \& Finanças (USP) & FEA/USP & $\begin{array}{c}1808- \\
057 X\end{array}$ & A2 \\
\hline
\end{tabular}


Antonio Gualberto Pereira, Tania Nunes e Rafael Rocha Simões

\begin{tabular}{|l|c|c|c|}
\hline Revista de Contabilidade e Organizações - RCO & FEA/USP/RP & $\begin{array}{c}1982- \\
6486\end{array}$ & A2 \\
\hline Revista Universo Contábil & FURB/SC & $\begin{array}{c}1809- \\
3337\end{array}$ & A2 \\
\hline BASE (UNISINOS) & UNISINOS/RS & $\begin{array}{c}1984- \\
8196\end{array}$ & B1 \\
\hline Contabilidade Gestão e Governança - CGG & UnB & $\begin{array}{c}1984- \\
3925\end{array}$ & B1 \\
\hline Custos e @gronegócio online & UFRPE & $\begin{array}{c}1808- \\
2882\end{array}$ & B1 \\
\hline Enfoque: Reflexão Contábil & UEM/PR & $\begin{array}{l}1984- \\
882 X\end{array}$ & B1 \\
\hline Revista de Educação e Pesquisa em Contabilidade - REPEC & Abracicon/DF & $\begin{array}{l}1981- \\
8610\end{array}$ & B1 \\
\hline
\end{tabular}

Fonte: elaborado pelos autores (2019), com base em dados da Plataforma Sucupira/CAPES para o quadriênio 2013-2016.

No quadro 1 são apresentados os 12 periódicos que se encontravam classificados entre os estratos A1 e B1 do Qualis Periódicos para a área 27 da CAPES (Administração Pública e de Empresas, Ciências Contábeis e Turismo), a instituição a qual pertencem, bem como o conceito Qualis a eles atribuído - não havia nenhum periódico pertencente ao estrato A1. Para elaboração do quadro, a partir da listagem disponibilizada no website da Associação Nacional de Programas de Pós-Graduação em Ciências Contábeis (AnpCont), foi conferida a classificação atual de cada um dos periódicos que constavam da referida lista, e seu Qualis foi atualizado quando notada divergência com a informação da Plataforma Sucupira/Capes.

\subsection{FONTES DE DADOS E ESTRATÉGIA DE BUSCA}

As fontes de dados para análise foram os websites dos periódicos listados no quadro 1. As consultas aos websites aconteceram entre junho de 2017 e janeiro de 2018 e os dados foram tabulados por meio de planilhas eletrônicas. O levantamento dos artigos e teses publicados abarcou o período de 2004 a 2017, tomando por base a primeira aplicação do ENADE para o curso de Ciências Contábeis.

No caso das teses, inicialmente a busca foi realizada no banco de dados digitais das IESs que ofertam cursos de doutorado na área contábil. Apenas na Universidade de São Paulo foram localizados registros que continham o termo "ENADE" no título e/ou como palavrachave. Adicionalmente, foi checada toda a produção referente ao período de existência do Exame, ano a ano, nesta base digital da USP, para a área de Controladoria e Contabilidade. Como dupla checagem, a busca foi realizada novamente na base da Biblioteca Digital Brasileira de Teses e Dissertações (BDTD). O termo "ENADE" foi utilizado no campo de busca, com abrangência geral (título, assunto etc.) e, na sequência, ativou-se o filtro para obter somente as teses - descartando-se as dissertações. Em seguida, foram eliminadas aquelas que não tinham relação com o curso de Ciências Contábeis.

Foram objeto de análise todas as teses e artigos disponíveis até 31 de dezembro de 2017 - na eventualidade de uma edição ter sido disponibilizada após essa data, não terá sido contemplada.

\subsection{CRITÉRIOS PARA A ANÁLISE}

A análise do material coletado foi realizada conforme as categorias a seguir. 
Nós por nós mesmos: evidências da produção acadêmica sobre o exame nacional de desempenho de estudantes (ENADE) em Ciências Contábeis

\subsubsection{Evolução da produção acadêmica}

Foi empregada uma análise quantitativa por ano, por periódico, bem como calculado o percentual com relação ao total geral de publicações.

\subsubsection{Aspectos qualitativos}

No presente estudo, foram replicados os itens bibliométricos utilizados por Ritta e Lavarda (2017), com as devidas adaptações/acréscimos necessários para melhor adequação à nossa proposta, que está voltada ao âmbito educacional da área contábil, com foco restrito a produções acadêmicas sobre o ENADE neste campo.

Dessa forma, foi analisado o conteúdo de cada artigo e tese, com relação aos seguintes itens: autores mais produtivos, teoria adotada, aspectos metodológicos, abordagem com relação ao ENADE. Para os artigos, adicionalmente foram analisados os tipos de fonte mais frequentes, bem como periódicos, artigos e livros mais referenciados.

Para a elaboração da rede produção/colaboração por autoria foram identificados e catalogados todos os autores formalmente identificados nos artigos e nas teses. A catalogação foi realizada utilizando um sistema alfanumérico composto pela letra " $A$ ", seguida de números em ordem crescente, indiciando por A01, A02, A03 e, assim, sucessivamente.

\subsubsection{Leis bibliométricas}

Dentre os indicadores bibliométricos mais utilizados, temos algumas leis cuja denominação está relacionada ao nome de seus autores: Lei de Lotka, de Zipf, de Bradford.

Lei de Lotka (Lei do Quadrado Inverso): estabelece parâmetros de medição da produtividade dos autores, utilizando um modelo de distribuição tamanho-frequência dos diversos autores relacionados a uma área de publicação. Baseia-se na ideia de que alguns pesquisadores publicam muito ao mesmo tempo em que muitos publicam pouco. Conforme Lotka, em qualquer área científica, a relação entre o número de autores e sua publicação é dada pela expressão $1 / \mathrm{n}^{2}$, ou seja, o inverso do quadrado. Dessa forma, analisando determinado período e um número $n$ de artigos, a quantidade de pesquisadores que publicam dois artigos seria de $1 / 4$ com relação àqueles que publicam somente um artigo, de 1/9 a daqueles que publicam três artigos, e assim por diante.

Lei de Zipf (ou Lei do Mínimo Esforço): fundamenta-se na medição da frequência de ocorrência das palavras em vários textos, com a obtenção de uma lista ordenada de termos de uma determinada disciplina ou assunto. Segundo Zipf (2016), se uma palavra tiver um baixo custo de utilização ou demanda um esforço mínimo para sua transmissão, esta será frequentemente utilizada em um texto longo.

Lei de Bradford (Lei de Dispersão): refere-se ao estabelecimento de núcleos e áreas de dispersão em relação à literatura em determinados conjuntos de publicações. É possível estimar o grau de relevância de periódicos de uma área do conhecimento, e as publicações que produzem um maior número de artigos sobre determinado assunto formam um núcleo de periódicos, supostamente de maior qualidade e relevância para a área (GUEDES; BORSCHIVER, 2005). Assim, a dispersão refere-se à formação de um núcleo de periódicos que atrai determinados assuntos emergentes.

Tendo explicitado a estruturação dos procedimentos metodológicos, apresentamos os resultados a seguir. 


\section{ANÁLISE DOS RESULTADOS}

Primeiramente, será apresentada a análise quantitativa da produção localizada e, na sequência, seus aspectos qualitativos (autoria, teorias, abordagem metodológica etc.). Por fim, é feita a análise segundo indicadores bibliométricos, utilizando as leis mencionadas no item anterior.

\subsection{ANÁLISE EVOLUTIVA DA PRODUÇÃO ACADÊMICA ENFOCANDO O ENADE}

Foram coletados 12 artigos e 4 teses no período de 2004 a 2017. Na Figura 2, apresentamos o número absoluto de artigos que tratam do ENADE, bem como o percentual relativo ao total de publicações no período analisado.

Figura 2 - Total de artigos sobre o ENADE, por ano



Fonte: elaborada pelos autores (2019).

Vale salientar que, embora o ENADE tenha entrado em vigor em 2004, para o curso de Ciências Contábeis foi aplicado pela primeira vez em 2006. Como a prova é aplicada no final do ano, o resultado é divulgado somente no ano seguinte. Assim, é compreensível que a primeira publicação encontrada date de 2008 - até mesmo por conta dos prazos dos periódicos para avaliação dos artigos recebidos, e eventuais solicitações de ajustes feitas aos autores. Embora haja mais um artigo em 2011 e dois em 2013, é somente a partir de 2015 que a produção acadêmica sobre esse tópico se torna constante anualmente.

Na Figura 2, nota-se que o pico de produções sobre o ENADE (3 artigos) ocorre nos dois últimos anos. No eixo direito do gráfico, temos o percentual com relação ao total de artigos publicados pelos periódicos analisados. Em 2016, essa temática representou quase 1\% do total de publicações da área naquele ano - restrito aos estratos A2 e B1 do Qualis/Capes.

Nesse período (2004 a 2017), foram publicados 3.625 trabalhos pelos 12 periódicos analisados, sendo que $0,33 \%$ discorriam sobre o ENADE. Se nos restringirmos à última década (2008-2017), o quadro não se altera muito: 3.010 artigos produzidos, 0,40\% deles abordando o ENADE. 
Nós por nós mesmos: evidências da produção acadêmica sobre o exame nacional de desempenho de estudantes (ENADE) em Ciências Contábeis

\subsection{ANÁLISE QUALITATIVA DA PRODUÇÃO ACADÊMICA ENFOCANDO O ENADE}

Nos subitens a seguir, os artigos são analisados com relação a: autoria, teoria utilizada, método de pesquisa empregado e abordagem adotada referente ao ENADE.

\subsubsection{Autoria}

Os 12 artigos analisados somam 38 autorias (com repetição de autores), o que resulta em uma média de 3,2 autores por artigo. Apenas um dos trabalhos possui autor único, sendo que a maior ocorrência é de quatro autores por artigo.

Na Figura 3, é apresentada a rede de pesquisadores com as respectivas instituições a quem estavam vinculados quando da publicação do artigo ou tese. Cada um dos 26 pontos representa um autor distinto, sendo destacadas as instituições às quais estão vinculados por meio do formato da figura e da cor dela; as linhas de ligação representam as colaborações em coautorias.

Figura 3 - Rede de Produção por Autoria e por IES



Fonte: elaborada pelos autores (2019), utilizando o programa Ucinet. 
Os autores enumerados na Figura 3 são descritos de forma nominal no quadro 2, com indicação da instituição à qual estavam vinculados à época da publicação. Para exemplificar a interpretação, o autor denominado A01, na Figura 3, corresponde a Antonio Carlos Ribeiro (que desenvolveu um trabalho individualmente) e era vinculado à Universidade Estadual de Feira de Santana (UEFS). O autor A4, que se apresenta como um importante nó de uma rede é Gilberto José Miranda, que era professor da Universidade Federal de Uberlândia (UFU) quando das publicações.

A Figura 3 permite identificar que, embora existam redes de pesquisa sobre o ENADE em diversas instituições e com variados autores, há um papel central da Universidade Federal de Uberlândia e do pesquisador Gilberto José Miranda. A atuação deste autor envolve coautoria principalmente com mestrandos e doutorandos, mas também abarca coautorias com docentes de outras IES, a exemplo da USP e da UFBA, entre outras.

Quadro 2 - Relação de autores identificados nos periódicos e teses

\begin{tabular}{|l|l|l|l|l|c|}
\hline $\begin{array}{l}\text { Antônio Carlos Ribeiro da } \\
\text { Silva }\end{array}$ & A01 & UEFS & $\begin{array}{l}\text { Tatianne Aparecida de Oliveira } \\
\text { Cardoso }\end{array}$ & A14 & UFU \\
\hline $\begin{array}{l}\text { Ana Larissa Alencar } \\
\text { Santana }\end{array}$ & A02 & $\begin{array}{c}\text { Centro Universitário } \\
\text { Lacerda }\end{array}$ & $\begin{array}{l}\text { Alessandra Vieira Cunha } \\
\text { Marque }\end{array}$ & A15 & UFU \\
\hline Alair José da Cruz & A03 & UNIIPAM & Dalton Francisco de Andrade & A16 & UFSC \\
\hline Gilberto José Miranda & A04 & UFU & Moises Balassiano & A17 & FUCAPE \\
\hline $\begin{array}{l}\text { Cleyde Cristina Rodrigues } \\
\text { Caetano }\end{array}$ & A05 & UFU & Edgar Bruno Cornacchione Jr & A18 & USP \\
\hline $\begin{array}{l}\text { Samuel de Paiva Naves } \\
\text { Mamede }\end{array}$ & A06 & UFU & Pablo Rogers & A19 & UFU \\
\hline $\begin{array}{l}\text { Brenda Cristina de } \\
\text { Oliveira Rodrigues }\end{array}$ & A07 & UFU & Marise Santana Resende & A20 & UFU \\
\hline $\begin{array}{l}\text { Raphael Vinicius Weigert } \\
\text { Camargo }\end{array}$ & A08 & UNESPAR & $\begin{array}{l}\text { Rita de Cássia Correa Pepinelli } \\
\text { Camargo }\end{array}$ & A21 & UFSC \\
\hline Vanessa Ramos da Silva & A09 & UFU & Sheizi Calheira de Freitas & A22 & UFBA \\
\hline Taís Duarte Silva & A10 & UFU & Janser Moura Pereira & A23 & FAMAT \\
\hline $\begin{array}{l}\text { Adriana Maria Procopio } \\
\text { de Araújo }\end{array}$ & A11 & FEARP & Nálbia de Araújo Santos & A24 & USP \\
\hline Valcemiro Nossa & A12 & FUCAPE & Arilda Teixeira & A25 & FUCAPE \\
\hline $\begin{array}{l}\text { Silvia Pereira de Castro } \\
\text { Casa Nova }\end{array}$ & A13 & USP & Antonio Cezar Bornia & A26 & UFSC \\
\hline
\end{tabular}

Nota: Para definição da IES de filiação do autor foram observados os metadados dos artigos e página de autoria das teses. No caso de mestrandos e doutorandos com atuação profissional em alguma IES, optou-se pela IES indicada como vínculo profissional, e para as demais a IES em que estavam estudando.

Fonte: elaborado pelos autores (2019).

Um complemento a esta análise de autoria pode ser encontrado quando se comenta a Lei de Lotka, conforme tópico 4.3 da análise dos resultados.

\subsubsection{Teoria utilizada}

A maior parte dos artigos (58,33\%) não faz menção explícita a uma teoria específica, enquanto outros $41,67 \%$ citam ao menos uma teoria. São citadas: Teoria da Função da Produção Educacional (25\%), Teoria da Resposta ao Item - como alternativa à Teoria Clássica dos Testes (8,33\%), Teoria Econômica da Educação (8,33\%), Modelo de três conjuntos de saberes de Paulo Freire $(16,66 \%)$.

Nas teses, o quadro é o seguinte: duas delas não deixam explícita uma teoria em específico, ainda assim, apresentam uma base teórica de autores para seu trabalho - por 
Nós por nós mesmos: evidências da produção acadêmica sobre o exame nacional de desempenho de estudantes (ENADE) em Ciências Contábeis

exemplo, a Pedagogia da Autonomia, de Paulo Freire. Nas outras duas teses são citadas as seguintes teorias: Teoria da Função de Produção da Educação (25\%), Modelo de três conjuntos de saberes de Paulo Freire (25\%).

\subsubsection{Aspectos metodológicos}

Antes de discorrer sobre os métodos empregados pelos artigos, vale uma observação: nenhum deles faz menção às dimensões ontológica e epistemológica da pesquisa empreendida. O foco da seção método - quando esta aparece como tal - limita-se a aspectos práticos e operacionais do estudo, envolvendo por vezes as ferramentas usadas. Sinteticamente, tem-se que:

- A maior parte dos artigos desenvolve um componente quantitativo no estudo como por exemplo: estatística descritiva (100\%), regressão linear múltipla (33,33\%), análise de correlação (25\%), modelo de componentes de variância $(16,66 \%)$, teste não paramétrico de Wilcoxon $(16,66 \%)$, regressão linear simples $(8,33 \%)$, regressão logística $(8,33 \%)$, análise multivariada $(8,33 \%)$, teste não paramétrico de Mann-Whitney (8,33\%), análise multinível $(8,33 \%)$, modelo logístico de três parâmetros (8,33\%);

- Os estudos são, predominantemente, descritivos, valendo-se de análise documental (100\%) e, por vezes, envolvendo a aplicação de questionário desenvolvido pelo autor (41,67\%).

Com relação às teses, apesar de tratar-se de um relatório final de pesquisas de doutoramento, não é feita menção explícita a dimensão ontológica e a epistemológica em nenhum dos trabalhos. Contudo, todas apresentam um componente estatístico como, por exemplo: estatística descritiva (100\%), regressão logística e MQO (50\%), análise fatorial confirmatória (25\%), HLM (25\%), entre outros, além de envolverem coleta de dados por meio de questionário (75\%) ou entrevista (25\%).

Uma limitação a ser destacada na presente pesquisa é a escolha de amostra, em que foram priorizadas publicações nacionais dos estratos A1, A2 e B1 do Qualis/CAPES, além das teses disponíveis nos bancos de dados virtuais das universidades brasileiras. Desta forma, os achados encontrados não descrevem a produção bibliográfica sobre o ENADE de forma mais ampla.

\subsubsection{Abordagem adotada}

Foram criadas 4 categorias, a fim de classificar os estudos com relação à abordagem adotada, como segue:

- Desempenho do aluno

- Formação do professor

- Características institucionais

- Outros

Todas as teses abordavam o desempenho discente, sendo que metade destas incluía também a formação docente. Duas delas ainda abarcavam as características institucionais em seu escopo.

Os artigos foram divididos nas mesmas 4 categorias. Dois dos trabalhos analisados abarcam mais de uma dimensão de análise: o artigo de Caetano, Cardoso, Miranda e Freitas (2015) relacionou o desempenho discente no ENADE com características institucionais da IES. 
O artigo de Cruz, Nossa, Balassiano e Teixeira (2013), por sua vez, discute a influência de aspectos curriculares, do número de docentes mestres e doutores e de características institucionais sobre a nota dos estudantes no ENADE de 2009. Além dos dois artigos citados, foram identificados mais três artigos que discutem formação discente, totalizando cinco artigos. Foram identificados quatro (de um total de 12 que abordam características institucionais e três voltados à discussão da formação docente).

Além destes temas, foram identificados como temas associados ao ENADE: currículo acadêmico; fatores psicológicos e pessoais (idade; uso de drogas; experiência profissional); modalidade do curso (EAD versus presencial); região geográfica; estudante com e sem necessidades especiais.

Os resultados apontam que, embora o tema desempenho do aluno seja o mais explorado nos artigos analisados, o tema características institucionais (e seu efeito sobre o desempenho discente) é bastante analisado, acompanhado pelo tema formação do professor (e seu efeito sobre o desempenho discente).

\subsubsection{Tipos de fontes}

Para os artigos, realizou-se a análise do tipo de fonte utilizado. Somados, os trabalhos referenciam 478 obras, dentre as quais foi observada a seguinte distribuição:

- Artigos: $237(50 \%)$

- Livros: 89 (19\%)

- Teses ou dissertações: 50 (10\%)

- Outros tipos de fontes: 102 (21\%)

Interessante notar que a maior parte das fontes utilizadas (60\%) são constituídas de trabalhos que passaram por uma avaliação acadêmica (artigos, teses, dissertações), contribuindo para a confiabilidade do conteúdo.

\subsubsection{Periódicos mais referenciados}

Também se restringindo aos artigos, analisou-se de quais periódicos advinham as publicações mais citadas. A Revista Contabilidade e Finanças (USP) foi a mais recorrente (7\% das publicações citadas), seguida pela Issues in Accounting Education (American Accounting Association), com $5 \%$ do total.

Destacamos como um indicativo de abrangência internacional das referências utilizadas o fato de quatro periódicos estrangeiros aparecerem entre os 11 mais frequentes.

\subsubsection{Artigos mais referenciados}

O artigo mais citado obteve 4 citações (1,9\%) - "O SINAES e o ENADE, da concepção à implantação", publicado pela Avaliação: Revista de Avaliação da Educação Superior. Com 3 citações (1,4\%), em segundo lugar ficou o artigo "Determinantes do desempenho acadêmico na área de Negócios", publicação da Revista Meta: Avaliação. Outros 11 artigos obtiveram duas citações ( $0,9 \%$ cada). Os demais tiveram apenas citação única.

\subsubsection{Livros mais referenciados}

O livro mais citado ( 3 vezes) pelos artigos aqui analisados, refere-se à elaboração de projetos de pesquisa - de autoria de Gil (1991). Outros 6 livros obtiveram duas citações cada, 
Nós por nós mesmos: evidências da produção acadêmica sobre o exame nacional de desempenho de estudantes (ENADE) em Ciências Contábeis

sendo dois deles relacionados a métodos estatísticos, dois sobre Educação em geral, e dois sobre aspectos da educação superior no Brasil.

\subsection{INDICADORES BIBLIOMÉTRICOS}

Nesta seção, são apresentados os resultados obtidos para as três leis bibliométricas abordadas no item de procedimentos metodológicos.

\subsubsection{Lei de Lotka}

O autor mais profícuo é Gilberto José Miranda, que produziu 8 dos artigos (67\% da produção total), além de uma tese de doutorado. Na segunda posição está Janser Moura Pereira, com 3 artigos (25\% da produção). Empatadas em terceiro lugar, com 2 artigos cada uma ( $17 \%$ do total), estão Sheizi Calheira de Freitas (também é autora de uma tese acerca do tema), Vanessa Ramos da Silva e Brenda Cristina de Oliveira Rodrigues.

Por meio de investigação da formação acadêmica e área de especialização desses autores que lideram as publicações nesta temática, tem-se que Miranda é Doutor em Contabilidade e Mestre em Administração; Pereira possui doutorado e Mestrado em Estatística e graduação em Matemática; Freitas é Doutora em Contabilidade e Mestra em Engenharia de Produção, com graduação em Ciências Contábeis. Silva e Rodrigues são mestras e graduadas em Ciências Contábeis.

Os demais 21 autores (81\%) apresentaram unicamente um artigo cada, sendo que entre eles há também a autora de uma das teses de doutoramento no tema em questão.

Assim, nossos achados estão de acordo com o estabelecido pela Lei de Lotka, de forma que poucos autores concentram a maior parte das publicações (como é o caso de Miranda, com $67 \%$ dos artigos), enquanto muitos produzem pouco (21 autores somados respondem por somente $8 \%$ do total de artigos).

\subsubsection{Lei de Zipf}

Foi realizada a aferição da frequência das palavras no conjunto dos 12 artigos e as 10 palavras mais citadas foram: desempenho (582 vezes), ENADE (532), alunos (517), Ciências (467), Contábeis (466), ensino (420), estudantes (402), cursos (402), IES (401) e Contabilidade (360). Nessa listagem, foram mantidos somente os termos de interesse, isto é, palavras como "que" ou "entre" foram desconsideradas. A contagem foi realizada pelo programa online Word Clouds (www.worldclouds.com), que possui algumas limitações, dentre as quais destacamos o fato de que considera apenas a grafia exata da palavra, ou seja, "ENADE" (532 menções) e "ENADE" (105 menções) são considerados como termos distintos entre si. Demais palavras que obtiveram citação superior a 200 vezes: curso (290), resultados (272), pesquisa (246), variáveis (241), instituições (240), Revista (237), formação (231), acadêmico (229), relação (217), Brasil (210), estudo (206), superior (205), avaliação (204).

A nuvem de palavras, apresentada na figura 04, permite visualizar as palavras mais recorrentes nos artigos analisados, com destaque para "desempenho" e "ENADE". 
Figura 4 - Nuvem de palavras dos artigos analisados

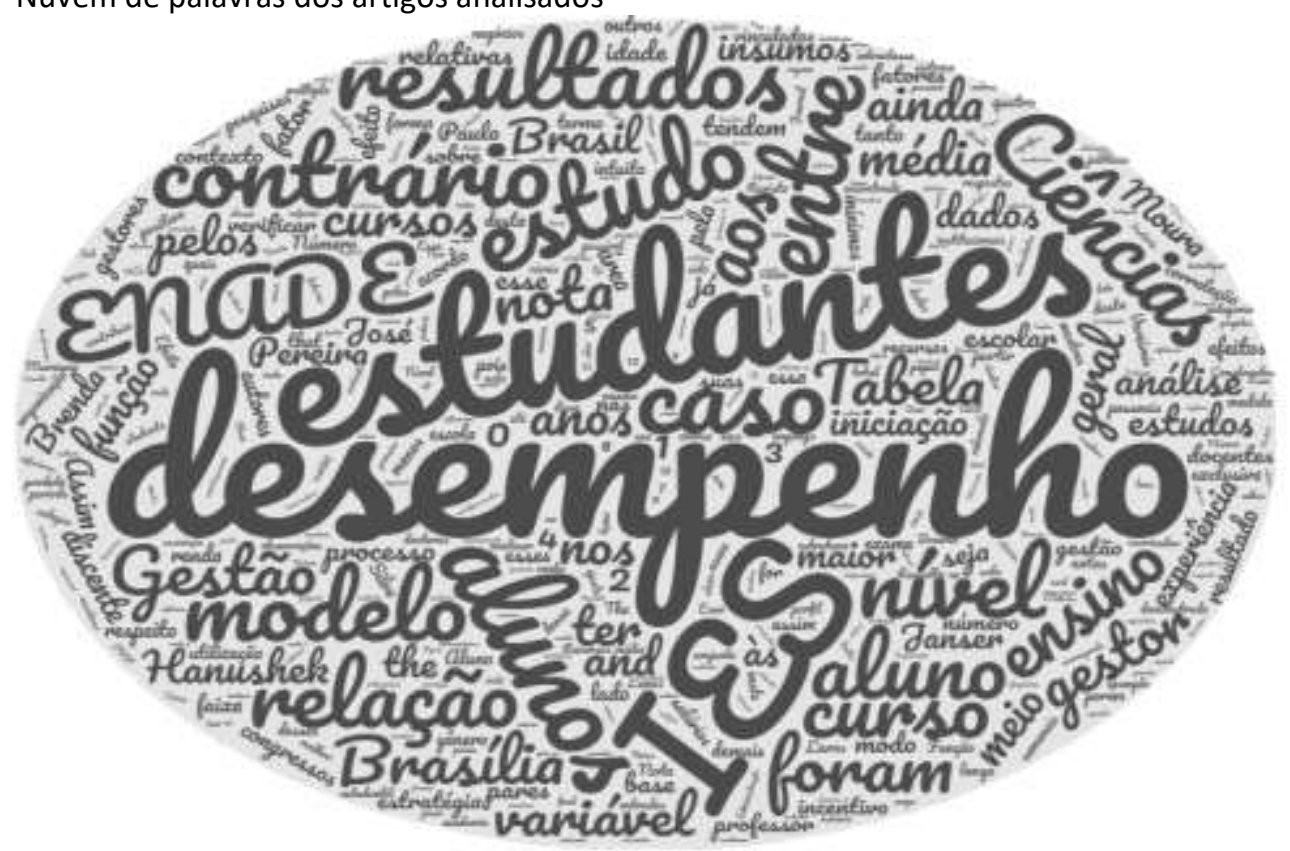

Fonte: elaborada pelos autores (2020).

A relação se mostra bem coerente com o tema dos artigos, que envolvem o ENADE, o ensino superior, especificamente, o curso de Ciências Contábeis. Também evidencia a natureza dos trabalhos, dada a frequência dos termos alunos/estudantes, IES, formação, avaliação, estudo/pesquisa, variáveis/resultado.

\subsubsection{Lei de Bradford}

A Revista Universo Contábil/FURB concentrou a maior produção de artigos enfocando o ENADE (4 artigos, ou seja, 33\% do total localizado), sendo seguida pela REPEC/Abracicon (2 artigos, isto é, 17\%). Em consonância com os termos da Lei de Bradford, pode-se considerar que tais periódicos constituem o núcleo dessa temática.

Apresentaram 1 artigo os periódicos: Advances in Science and Applied Accounting/AnpCont, Brazilian Business Review/FUCAPE, Contabilidade Vista e Revista/UFMG, Revista Brasileira de Gestão e Negócios/FUCAPE, Contabilidade, Gestão e Governança/UnB e Enfoque: Reflexão Contábil (UEM/Paraná). Esses 6 periódicos constituem a área de dispersão em relação à literatura sobre o ENADE, de acordo com a Lei de Bradford.

Vale mencionar que um terço dos periódicos revisados não apresentou nenhum artigo enfocando o ENADE. Entre eles estão a Revista de Contabilidade e Finanças da USP e a Revista de Contabilidade e Organizações (FEA-USP/Ribeirão Preto); os outros dois são pertencentes ao estrato B1 - Base/Unisinos, e Custos e @gronegócio online/UFRPE. 
Nós por nós mesmos: evidências da produção acadêmica sobre o exame nacional de desempenho de estudantes (ENADE) em Ciências Contábeis

Adicionalmente, observa-se que a distribuição dos 12 artigos entre os 12 periódicos analisados, com relação ao estrato Qualis/CAPES, foi a seguinte:

- Publicados em periódicos A1: nenhum;

- Publicados em periódicos A2: 67\% (8 artigos);

- Publicados em periódicos B1: 33\% (4 artigos).

Já as teses localizadas foram todas produzidas pelo Programa de Pós-Graduação em Controladoria e Contabilidade (PPGCC) da Universidade de São Paulo, Faculdade de Economia, Administração e Contabilidade (FEA). As defesas ocorreram entre 2011 e 2014, com a maior produção observada em 2012 (Tabela 1).

Tabela 1 - Distribuição da produção de teses abordando o ENADE, por ano

\begin{tabular}{c|c|c|c|c|c|c|c|c|c|c|c}
\hline $\mathbf{2 0 0 7}$ & $\mathbf{2 0 0 8}$ & $\mathbf{2 0 0 9}$ & $\mathbf{2 0 1 0}$ & $\mathbf{2 0 1 1}$ & $\mathbf{2 0 1 2}$ & $\mathbf{2 0 1 3}$ & $\mathbf{2 0 1 4}$ & $\mathbf{2 0 1 5}$ & $\mathbf{2 0 1 6}$ & $\mathbf{2 0 1 7}$ & TOTAL \\
\hline 0 & 0 & 0 & 0 & 1 & 2 & 0 & 1 & 0 & 0 & 0 & 4 \\
\hline
\end{tabular}

Fonte: elaborada pelos autores (2020), com base nos bancos de teses das universidades pesquisadas e da BDTD.

Desse total, já foram excluídas teses que não tratavam do curso de Ciências Contábeis (abordavam Pedagogia, Direito, Medicina...), como também as publicações de outros níveis acadêmicos, como Dissertações de Mestrado.

\section{CONSIDERAÇÕES FINAIS}

Considera-se que o objetivo principal deste trabalho, desenvolver um levantamento sistemático da produção acadêmica sobre o ENADE na área de Contabilidade, foi atingido. Recapitulando a resposta do artigo para os objetivos específicos, temos que: (i) escanear os periódicos nacionais com maior classificação no Qualis - CAPES: foi empreendida, da qual resultaram 12 artigos que foram destrinchados mais detalhadamente; (ii) analisar quantitativa e qualitativamente os artigos localizados, incluindo a verificação de indicadores bibliométricos propostos na literatura: envolveu os seguintes tópicos: autoria, teoria utilizada, aspectos metodológicos, abordagem adotada, tipos de fontes, periódicos, artigos e livros mais referenciados; a análise quantitativa, incluindo indicadores bibliométricos, foi cumprida conforme proposto; (iii) sintetizar graficamente a evolução da produção sobre esse tópico no período de 2004 a 2017: revelou que mais da metade da produção ( 8 artigos) se concentrou nos últimos três anos deste período.

Retomando a questão de pesquisa - Qual a tendência e as características da produção acadêmica que enfoca o Exame Nacional de Desempenho de Estudantes (ENADE) na área de Ciências Contábeis? -, podemos destacar como características: um número reduzido de autores se dedicando a essa temática (26 durante todo o período analisado), sendo que tais pesquisas são feitas em grupos de 3 a 4 pesquisadores. Embora as teses apresentem uma teoria ou um grupo de autores para embasamento teórico, isso nem sempre ocorre no caso dos artigos - que, ressalta-se, integram os periódicos dos estratos A2 e B1 do Qualis/CAPES. A utilização de recursos estatísticos é amplamente utilizada (64\% dos artigos e $100 \%$ das teses), contudo, os aspectos metodológicos limitam-se à indicação de operacionalização, carecendo de abordagem mais filosófica (dimensões ontológica e epistemológica) - o que não é incomum em estudos da área contábil como um todo. Não é surpresa que as teses apresentem um rigor teórico e metodológico maior que o dos artigos revisados.

$O$ desempenho discente é abordado com maior frequência nessa produção acadêmica, entretanto, características institucionais e a formação do professor também são alvo constante de tais trabalhos. Tem-se que $60 \%$ das referências utilizadas por esses trabalhos são 
de natureza acadêmica (artigos científicos, teses e dissertações). O periódico com mais publicações citadas é nacional (Revista Contabilidade e Finanças da USP), e não houve um artigo ou livro com destaque extraordinário.

Tais achados permitem identificar algumas lacunas interessantes na produção sobre o ENADE: são escassos os trabalhos com abordagens críticas e interpretativistas sobre o ENADE; há carência de trabalhos que utilizem uma ou mais teorias para fundamentar estudos sobre desempenho discente, características das Instituições de Ensino Superior, formação de professor e outras temáticas; há espaços para os desenvolvimento de redes de pesquisa entre laboratórios de pesquisa de IES nacionais, com destaque para uma concentração da produção no pesquisador Gilberto Miranda e na Universidade Federal de Uberlândia.

Os achados referentes a indicadores bibliométricos específicos mostram que: a Lei de Lotka é ratificada (enquanto um dos autores concentra $2 / 3$ da produção total, mais de $80 \%$ dos autores respondem por somente $8 \%$ das publicações); dois periódicos (RUC/FURB e REPEC/Abracicon) constituem o núcleo de divulgação de pesquisas sobre o ENADE, conforme a Lei de Bradford - e todas as teses sobre o tema foram produzidas por pesquisadores do PPGCC da FEA-USP; e, pela aferição de frequência proposta na Lei de Zipf, notamos que termos como desempenho, formação e avaliação estão entre os mais frequentes nas pesquisas aqui investigadas.

Com relação à tendência, pode-se considerar que, embora os dados descritivos representem uma descrição do período analisado, a concentração de estudos no último triênio aparece como um indicativo de que não será inesperado se for observado um aumento na quantidade de pesquisas relacionadas ao tema, mesmo porque ainda há muito a ser explorado com relação à avaliação do ensino superior em Ciências Contábeis, e o ENADE integra o principal modelo em vigor atualmente no país. Como oportunidade para pesquisas futuras, sugere-se a análise de um período maior disponível (atualmente, foram 4 edições de exames para o curso de Ciências Contábeis).

\section{REFERÊNCIAS}

ALKIN, M. C.; VO, A. T. Evaluation essentials: From A to Z. Guilford Publications, 2017.

ARAÚJO, C. A. A. Bibliometria: evolução histórica e questões atuais. Em questão, v. 12, n. 1, p. 11-32, 2006.

Brasil. Lei n. 10.861, de 14 de abril de 2004. Institui o Sistema Nacional de Avaliação da Educação Superior - SINAES e dá outras providências. Disponível em:

http://www.planalto.gov.br/ccivil_03/_ato2004-2006/2004/lei/l10.861.htm. Acesso em: 24 mar. 2019.

BRITO, M. R. F. O SINAES e o ENADE: da concepção à implantação. Revista de Avaliação da Educação Superior, v.13, n.3, p. 841-850, 2008.

BYRNE, M.; FLOOD, B. Assessing the teaching quality of accounting programmes: an evaluation of the course experience questionnaire. Assessment \& Evaluation in Higher Education, v. 28, n. 2, p. 135-145, 2003. 
Nós por nós mesmos: evidências da produção acadêmica sobre o exame nacional de desempenho de estudantes (ENADE) em Ciências Contábeis

CAETANO, C. C. R.; CARDOSO, T. A. O.; MIRANDA, G. J.; FREITAS, S. C. Desempenho no ENADE em ciências contábeis: ensino a distância (EAD) versus presencial. Revista Universo Contábil, v. 11, n. 4, p. 147-165, 2015. DOI: 10.4270/ruc.2015436.

CASTRO, M. H. G. Avaliação do sistema educacional brasileiro: tendências e perspectivas. MEC, Instituto Nacional de Estudos e Pesquisas Educacionais, 1998.

CENSO DA EDUCAÇÃO SUPERIOR. Instituto Nacional de Estudos e Pesquisas Educacionais Anísio Teixeira. Ministério da Educação. 2015. Recuperado de:

http://download.inep.gov.br/educacao_superior/censo_superior/apresentacao/2015/Apres entacao_Censo_Superior_2015.pdf. Acesso em: 24 mar. 2019.

CRUZ, A. J.; NOSSA, V.; BALASSIANO, M.; TEIXEIRA, A. Desempenho dos alunos no ENADE de 2009: um estudo empírico a partir do conteúdo curricular dos cursos de ciências contábeis no Brasil. Advances in Scientific and Applied Accounting, v. 6, n. 2, p. 178-203, 2013.

FARIA, J. A.; GOMES, S. M. S.; DIAS FILHO, J. M.; ALBUQUERQUE, V. A assimetria da informação na elaboração do orçamento: uma análise da produção científica nos periódicos internacionais entre 2005 e 2009. Contabilidade Vista \& Revista, v. 22, n. 2, p. 43-65, 2011.

FONSECA, E. N. Bibliometria: teoria e prática. Editora Cultrix, 1986.

FREITAS, L. C.; MALAVASI, M. M. S.; SORDI, M. R. L.; MENDES, G. S. C. V.; ALMEIDA, L. C. Avaliação e políticas públicas educacionais: ensaios contrarregulatórios em debate. Campinas: Leitura Crítica, 2012.

GIL, A. C. Como elaborar projetos de pesquisa. 4. ed. São Paulo: Atlas, 2002.

GIRÃO, L. F. D. A. P.; MACHADO, M. R. A produção científica sobre assimetria informacional em periódicos internacionais de contabilidade. Revista Contabilidade e Controladoria, v.5, n. 1, p. 99-119, 2013. doi: http://dx.doi.org/10.5380/rcc.v5i1.29923.

GUEDES, V. L. S.; BORSCHIVER, S. Bibliometria: uma ferramenta estatística para a gestão da informação e do conhecimento, em sistemas de informação, de comunicação e de avaliação científica e tecnológica. Encontro Nacional de Ciência da Informação, v. 6, n. 1, p. 18, 2005.

LEITÃO, T. M. S. D. P.; MORICONI, G. M.; ABRÃO, M.; SILVA, D. S. D. Análise acerca do boicote dos estudantes aos exames de avaliação do ensino superior. Estudos em Avaliação Educacional, v. 21, n. 45, p. 87-106, 2010.

LEVITON, L. C.; BORUCH, R. F. Contributions of evaluation to education programs and policy. Evaluation Review, v. 7, n. 5, p. 563-598, 1983.

MINISTÉRIO DA EDUCAÇÃO E CULTURA (MEC). Portaria Normativa № 40, de 12 de dezembro de 2007 (republicada em 29 de dezembro de 2010). Institui o e-MEC, sistema eletrônico de fluxo de trabalho e gerenciamento de informações relativas aos processos de regulação, avaliação e supervisão da educação superior no sistema federal de educação (...). Diário 
Oficial União. Republicada por ter saído, no DOU no 239, de 13-12-2007, Seção 1, págs. 39 a 43, com incorreção no original.

MINISTÉRIO DA EDUCAÇÃO E CULTURA MEC). Cursos insatisfatórios serão tratados com rigor pelo MEC. Assessoria de Comunicação Social. Recuperado de:

http://portal.mec.gov.br/ultimas-noticias/212-educacao-superior-1690610854/32921cursos-insatisfatorios-serao-tratados-com-rigor-pelo-mec. Acesso em: 24 mar. 2019.

MINISTÉRIO DA EDUCAÇÃO E CULTURA (MEC). Ministro anuncia indicadores de qualidade e medidas para cursos insatisfatórios. Recuperado de: http://portal.mec.gov.br/ultimasnoticias/212-educacao-superior-1690610854/20990-ministro-anuncia-indicadores-dequalidade-e-medidas-para-cursos-insatisfatorios. Acesso em: 24 mar. 2019.

MINISTÉRIO DA EDUCAÇÃO E CULTURA (MEC). Instituto Nacional de Estudos e Pesquisas Educacionais Anísio Teixeira. Manual do ENADE 2016. Recuperado de http://download.inep.gov.br/educacao_superior/ENADE/manuais/manual_do_ENADE_2809 2016.pdf. Acesso em: 24 mar. 2019.

MIRANDA, G. J. Relações entre as qualificações do professor e o desempenho discente nos cursos de graduação em contabilidade no Brasil. (Tese de doutorado), Universidade de São Paulo, São Paulo, SP, Brasil, 2011.

NASCIMENTO, A. R. D.; JUNQUEIRA, E.; MARTINS, G. A. Pesquisa acadêmica em contabilidade gerencial no Brasil: análise e reflexões sobre teorias, metodologias e paradigmas. RAC - Revista de Administração Contemporânea, v. 14, n. 6, 2010. http://dx.doi.org/10.1590/S1415-65552010000700008.

NEVO, D. The conceptualization of educational evaluation: An analytical review of the literature. Review of Educational Research, v. 53, n. 1, p. 117-128, 1983.

OKUBO, Y. Bibliometric indicators and analysis of research systems: methods and examples. 1997.

PEDROSA, R. H. L. Professor da Unicamp opina sobre decisão da USP de cooperar com o ENADE: "as melhores universidades do País não devem se omitir". Revista Ensino Superior Unicamp, 2013. Disponível em:

http://www.revistaensinosuperior.gr.unicamp.br/notas/professor-da-unicamp-opina-sobredecisao-da-usp-de-cooperar-com-o-ENADE-as-melhores-universidades-do-pais-nao-devemse-omitir. Acesso em: 30 jul. 2019.

PRITCHARD, A. Statistical bibliography or bibliometrics. Journal of documentation, v. 25, n. 4, p. 348-349, 1969.

RIBEIRO, H. C. M. Análise das pesquisas sobre auditoria publicadas em periódicos brasileiros. Advances in Scientific and Applied Accounting, v. 8, n. 1, p. 88-112, 2015. 
Nós por nós mesmos: evidências da produção acadêmica sobre o exame nacional de desempenho de estudantes (ENADE) em Ciências Contábeis

RIBEIRO, H. C. M. Quinze anos de produção acadêmica do tema contabilidade internacional: uma análise bibliométrica em periódicos brasileiros. Revista de Educação e Pesquisa em Contabilidade (REPeC), v. 8, n. 3, 2014.

RITTA, C. O; LAVARDA, C.E.F. Aspectos da produção científica sobre controle gerencial. Revista de Administração FACES Journal, Belo Horizonte, v. 16, n. 3, p. 105-124, 2017. http://dx.doi.org/10.21714/1984-6975FACES2017V16N3ART4154.

RODRIGUES, V. A.; PEIXOTO, M. C. L. Desvendando a Caixa Preta do ENADE: Considerações sobre o Processo de Avaliação. Trabalho \& Educação, v. 18, n. 2, p. 47-61, 2009.

ROTHEN, J. C.; BARREYRO, G. B. Expansão da educação superior no Brasil e avaliação institucional: um estudo do Sistema Nacional de Avaliação da Educação Superior (SINAES). Revista Avaliação. Série-Estudos, n. 30, p. 167-181, 2010.

SANTOS, P. S. M. B. Guia prático da política educacional no Brasil: ações, planos, programas e impactos. São Paulo: Cengage Learning, 2012.

SANTOS, V.; BEUREN, I. M.; NARDI, L. V.; VICENTI, T. Folga Orçamentária: Características das Publicações em Periódicos Internacionais. Contabilidade Vista \& Revista, v. 27, n. 1, 2016.

SOUSA, S. M. Z. L. Possíveis impactos das políticas de avaliação no currículo escolar. Cadernos de Pesquisa, n. 119, p. 175-190, 2003.

STAKE, R.; BECHER, E. Evaluation Essentials Types of. Disponível em: http://blog-familymatters.extension.umn.edu/2017/06/evaluation-essentials-types-of.html. Acesso em: 24 mar. 2019.

TAGUE-SUTCLIFFE, J. An introduction to informetrics. Information processing \& management, v. 28, n. 1, p. 1-3, 1992.

THEÓPHILO, C. R.; IUDÍCIBUS, S. Uma Análise Crítico-Epistemológica da Produção Científica em Contabilidade no Brasil. Contabilidade, Gestão e Governança, v. 8, n. 2, p. 147-175, 2005.

ZIPF, G. K. Human behavior and the principle of least effort: An introduction to human ecology. Ravenio Books, 2016. 